\title{
QUANTIFYING THE SINGLE LEG BALANCE USING MULTIPLE DYNAMIC POSTURES ON STABLE SURFACE
}

\section{R.Vinodh Rajkumar.}

Physiotherapist \& Anthropologist, Director - Prabhanjeet Fitness Research Institute OPC Private Limited, Bangalore, Karnataka, India.

\section{ABSTRACT}

Introduction: Singe leg balance (SLB) is a key neuro-biomechanical asset of several fundamental and advanced closed kinetic chain activities of lower limbs. From the perspectives of healthy ageing and fall prevention strategies, there is a compelling need to explore and devise a safe and effective SLB assessment tool to incorporate in multifactorial health evaluations and gerontological education.

Methodology: About twenty dynamic SLB exercise techniques were opted and used as assessment techniques to build a dynamic SLB assessment scale.

Results: As a preliminary testing, when this assessment scale was applied on non-athlete individuals in the age group of 35 to 50 years old, nine men (Mean body weight $=79 \mathrm{Kg}$, Mean fat percentage $=32$ ) and five women (Mean body weight $=65 \mathrm{Kg}$, Mean fat percentage = 36), who have been exercising two to three days per week under the supervision of exercise professional, they displayed excellent SLB in almost all the techniques.

Conclusion: It is prudent to utilize this dynamic SLB assessment scale not only to diagnose and quantify SLB performance but also to motivate the individuals by giving the highest rating even if the individuals display precise SLB only after multiple trials and errors. Numerous such simple, inexpensive and non-invasive diagnostic tools are needed in the health education and health care system.

KEY WORDS: Single leg balance, Ageing, Falls among the elderly, Physical Therapy, Geriatrics, Gerontology.

Address for correspondence: R.Vinodh Rajkumar, Physiotherapist \& Anthropologist, Director Prabhanjeet Fitness Research Institute OPC Private Limited, Bangalore, Karnataka, India.

E-Mail: dreamofkalam@rediffmail.com

Access this Article online

Quick Response code

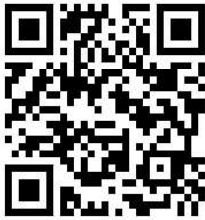

DOI: $10.16965 /$ ijpr.2020.130

Journal Information

International Journal of Physiotherapy and Research

ISSN (E) 2321-1822 | ISSN (P) 2321-8975

https://www.ijmhr.org/ijpr.html

DOI-Prefix: https://dx.doi.org/10.16965/ijpr

Article Information

Received: 12 Apr 2020

Peer Review: 13 Apr 2020

Revised: None
Accepted: 15 May 2020

Published (O): 11 Jun 2020

Published (P): 11 Jun 2020

\section{INTRODUCTION}

Singe leg balance (SLB) is a key neuro-biomechanical asset of several fundamental and advanced closed kinetic chain activities of lower limbs. SLB is both neurologically and biomechanically challenging task to support the body weight on a smaller base of support offered by single foot, counteracting the effects of gravitational force.

The ability to control balance is based on the integration of sensory information from the somatosensory, vestibular, and visual systems, which work together with the nervous-muscular system to control body alignment with respect to the environment and to stabilize the body's centre of mass during perturbations, with subsequent motor output [1]. Relying on a single leg base of support requires the postural control system to reorganize the total body center of mass over a narrow base of support [2]. But still, SLB is effortlessly blended in the locomotor functions like walking, stair climbing and running under the tutelage of innate faculties like co-contraction of muscles and various other coordinated posture-detecting and posture 
-controlling mechanisms of nervous system and sensory organs. As the innate faculties get deteriorated, though the age of onset of this deterioration could be highly individual-specific, various individuals especially older adults experience difficulty in sustaining SLB even on stable surface and this could have a devastating impact on the biomechanical parameters of even basic functions like walking.

Increased postural sway and high fall rates in children (incomplete maturation of neuromuscular system) and seniors (ageing-induced declines of the neuromuscular system) seems to be counteracted with higher Tibialis Anterior (TA)/ Soleus (SO) co-activity and SO modulation, but aging-induced decline of TA motor units might account for deteriorations of TA modulation in seniors [3]. It is also quite obvious that people are seldom informed about the status of their SLB when they were young or at least during middle adulthood, therefore various mechanisms linked to SLB could go dysfunctional almost irreversibly, increasing the risks of fall during the ageing. Falls among the elderly are one of the major causes of morbidity and mortality worldwide and they constitute the second leading cause of unintentional deaths after road-traffic accidents [4]. Females have a higher risk of fall comparatively to males and the major contributing factors for fall injuries are aging, visual impairment, previous history of fall, depression, and gait problem [5]. While challenges and barriers exist, fall prevention strategies can be incorporated into clinical practice [6]. Use of multifactorial assessments and interventions has led to a decrease in fall rates by $25 \%$ to $40 \%$ and risk of falling could be reduced by modifying known risk factors [7]. From the perspectives of healthy ageing and fall prevention strategies, there is a compelling need to explore and devise a safe and effective SLB assessment tool to incorporate in multifactorial health evaluations, disease rehabilitation programs and gerontological education.

\section{METHODOLOGY}

Constructing a dynamic SLB assessment scale based on the dynamic SLB exercises prescribed for the individuals in the age group $15-55$ years old, who has been engaging in structured physical activity for purposes like weight loss, exer- cise-based rehabilitation and overall health but not for competitions. These SLB exercises has been generally administered with eyes open on stable platform to ensure safety whilst the challenges would be basically enhanced by altering the alignment of trunk, unsupported leg (UL) and the arms, in addition, by altering the alignment of the support leg (SL) in some exercise variations. Table 1 and Figure 1 to 20 describe the twenty SLB exercises that were opted and used as assessment techniques to build this non-invasive dynamic SLB assessment scale.

In order to convert these exercise variations in to an assessment scale, the easily observable postural strategies displayed by the individuals can be used in rating the SLB control for each assessment technique. Figure 21 shows such postural strategies like (i) Quickly lowering the UL and dismantling the SLB posture (ii) Medially or laterally displacing the foot of the SL (iii) Hopping on the SL in any unexpected direction to a different location (not shown in Figure 21). However, in the perfect dynamic SLB manoeuvres, effective stabilization of the SL without any of these postural strategies is evident.

Fig. 1: Forward lunge to SLB.

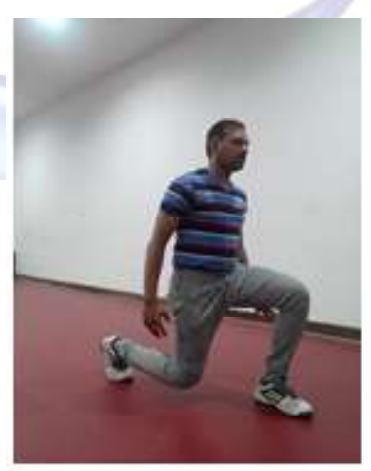

1(a)

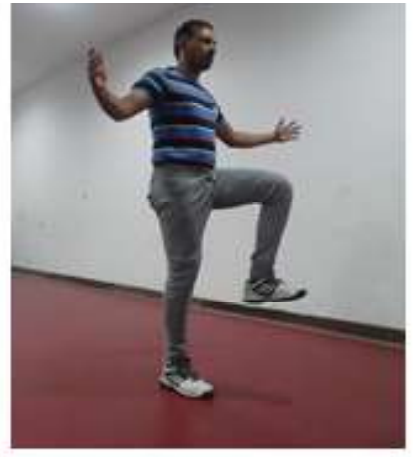

1 (b)
Fig. 2: Backward lunge to SLB.

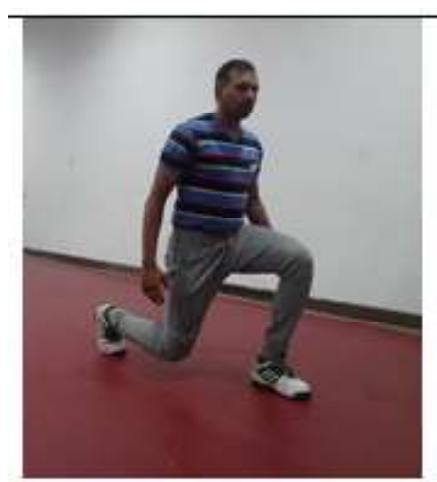

2 (a)

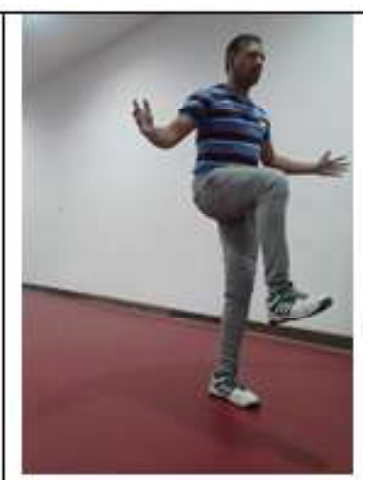

2 (b) 
R. Vinodh Rajkumar. QUANTIFYING THE SINGLE LEG BALANCE USING MULTIPLE DYNAMIC POSTURES ON STABLE SURFACE.

Table 1: Dynamic SLB exercise variations. [Links for brief videos of these techniques - https://www.youtube.com/ watch?v=CGji9vcjDKU ]

\begin{tabular}{|c|c|}
\hline TECHNIQUES & DESCRIPTION \\
\hline Forward lunge to SLB & $\begin{array}{l}\text { Figure } 1 \text { - From SLB, bring one foot forward and lunge. From lunge, take the same foot backwardly } \\
\text { off the ground to regain SLB. }\end{array}$ \\
\hline Backward lunge to SLB & $\begin{array}{l}\text { Figure } 2 \text { - From SLB, bring one foot backward and lunge. From lunge, take the same foot forwardly } \\
\text { off the ground to regain SLB. }\end{array}$ \\
\hline Sideward reach to SLB & $\begin{array}{l}\text { Figure } 3 \text { - Tilt the body towards right or left side. Take the foot (of the side of leaning) off the } \\
\text { ground to SLB. }\end{array}$ \\
\hline Squat to SLB & Figure 4 - Perform half-depth squat. From squat, lift any foot off the ground to SLB. \\
\hline Sideward bending on SLB (Ipsilateral) & $\begin{array}{l}\text { Figure } 5 \text { - From SLB, tilt the body to the support leg side. Knee of the support leg can be slightly } \\
\text { flexed (to get eccentric control). Raise the tilted body and regain SLB. }\end{array}$ \\
\hline Side bend to SLB (Contralateral) & $\begin{array}{l}\text { Figure } 6 \text { - From SLB, tilt the body opposite to the support leg side. The unsupported leg can be } \\
\text { brought backward to the support leg. Knee of the support leg can be slightly flexed (to get } \\
\text { eccentric control). Raise the tilted body and regain SLB. }\end{array}$ \\
\hline Bend and twist to SLB & $\begin{array}{l}\text { Figure } 7 \text { - Forward bend and twist the trunk and raise the body directly to SLB. If the twist is } \\
\text { towards left side, SLB should be on the right foot. }\end{array}$ \\
\hline Heel off on SLB & $\begin{array}{l}\text { Figure } 8 \text { - Stand on single leg with the knee of the support leg slightly flexed. Extend the knee of } \\
\text { the support leg (to give momentum) and raise the heel of the support leg off the ground and } \\
\text { return to SLB. }\end{array}$ \\
\hline Forward leaning with arm and leg raise on SLB & $\begin{array}{l}\text { Figure } 9 \text { - Stand on single leg. Lean forward accompanied by raising of the arm and leg of the } \\
\text { opposite side and return to SLB. }\end{array}$ \\
\hline On the spot hopping on SLB & Figure $10-$ Stand on single leg. Hop on the spot and regain SLB. \\
\hline Forward hopping and progress on SLB & Figure 11 - Stand on single leg. Hop forward and freeze on SLB. \\
\hline Side to side hopping on SLB & $\begin{array}{l}\text { Figure } 12 \text { - Stand on single leg. Hop to the left and freeze on SLB. Hop to the right and freeze on } \\
\text { SLB. }\end{array}$ \\
\hline Zig zag forward hopping and progress on SLB & $\begin{array}{l}\text { Figure } 13 \text { - Stand on single leg. Hop diagonally forward to left and right and progress } \\
\text { accompanied by SLB freeze after every hop. }\end{array}$ \\
\hline Stride forward to SLB & Figure 14 - Take a stride forwardly. Take the hind leg forward off the ground to attain SLB. \\
\hline Stride backward to SLB & Figure 15 - Take a stride backwardly. Take the fore leg backward off the ground to attain SLB. \\
\hline Stride sideward to SLB (Ipsilateral) & Figure 16 - Take a stride sideward. Attain SLB on the leg that has moved sideward. \\
\hline Stride sideward to SLB (Contralateral) & $\begin{array}{l}\text { Figure } 17 \text { - Take a stride sideward crossing opposite leg from front. Attain SLB on the leg that has } \\
\text { crossed and moved sideward. }\end{array}$ \\
\hline Step up knee lift to SLB & $\begin{array}{l}\text { Figure } 18 \text { - From the ground, take a forward step to the stepper }(20 \mathrm{~cm} \text { high). Swing the hind leg } \\
\text { forwardly and attain SLB on the leg placed on the stepper. }\end{array}$ \\
\hline Step down and reverse step up to SLB & $\begin{array}{l}\text { Figure } 19 \text { - From the stepper ( } 20 \mathrm{~cm} \text { high), take a forward step to the ground. Swing the fore leg } \\
\text { backwardly and attain SLB on the leg placed on the stepper. }\end{array}$ \\
\hline Sideward bending and side step up to SLB & $\begin{array}{l}\text { Figure } 20 \text { - Place a foot on the stepper ( } 20 \mathrm{~cm} \text { high). Bend sideward towards the ground. Raise the } \\
\text { body to upright posture accompanied by sideward step up and attain SLB on the leg placed on } \\
\text { the stepper. }\end{array}$ \\
\hline
\end{tabular}

Fig. 3: Sideward reach to SLB.

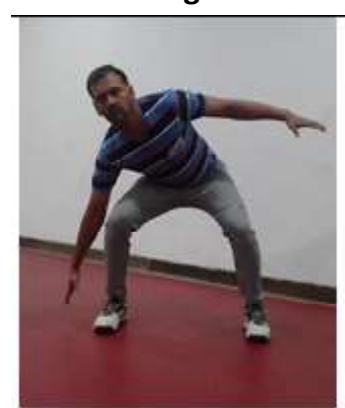

3 (a)

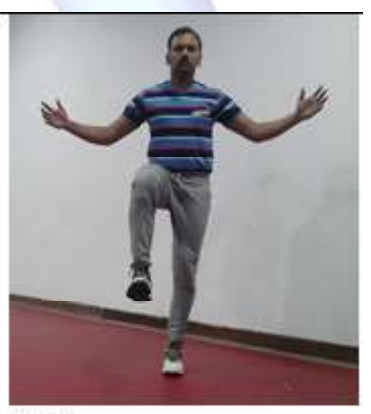

3 (b)

Fig. 4: Squat to SLB.

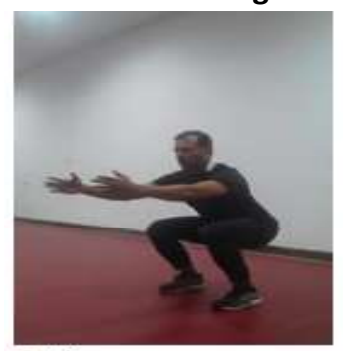

4 (a)

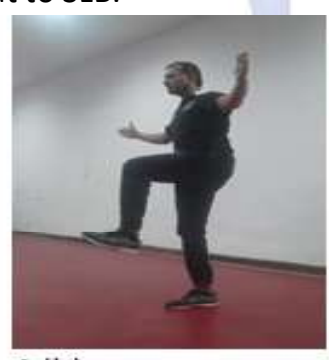

4 (b)

Fig. 5: Sideward bending on SLB (Ipsilateral).

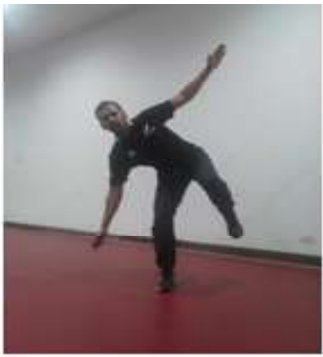

5 (a)

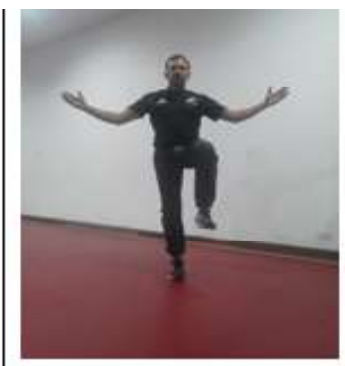

5 (b)

Fig. 6: Sideward bending on SLB (Contralateral).

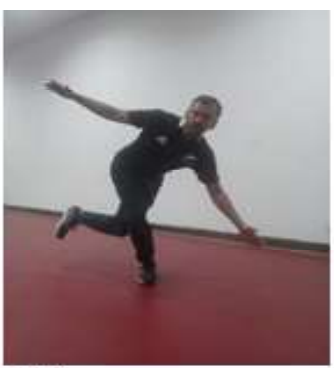

6 (a)

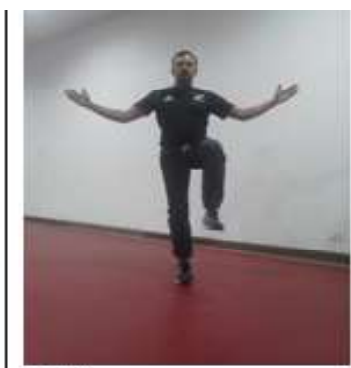

6 (b)

Int J Physiother Res 2020;8(3):3462-70. I ISSN 2321-1822 
R. Vinodh Rajkumar. QUANTIFYING THE SINGLE LEG BALANCE USING MULTIPLE DYNAMIC POSTURES ON STABLE SURFACE.

Fig. 7: Bend and twist to SLB.

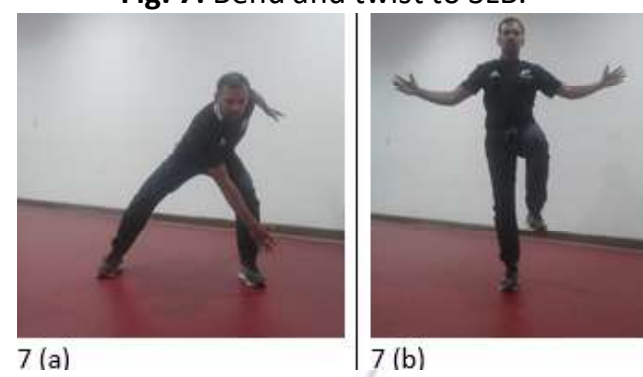

Fig. 8: Heel off on SLB.

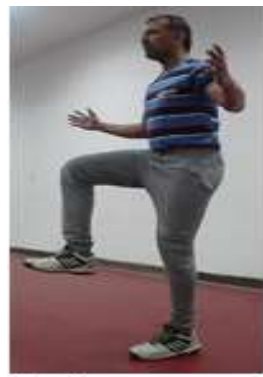

8 (a)

Fig. 9: Forward leaning with arm and leg raise on SLB.
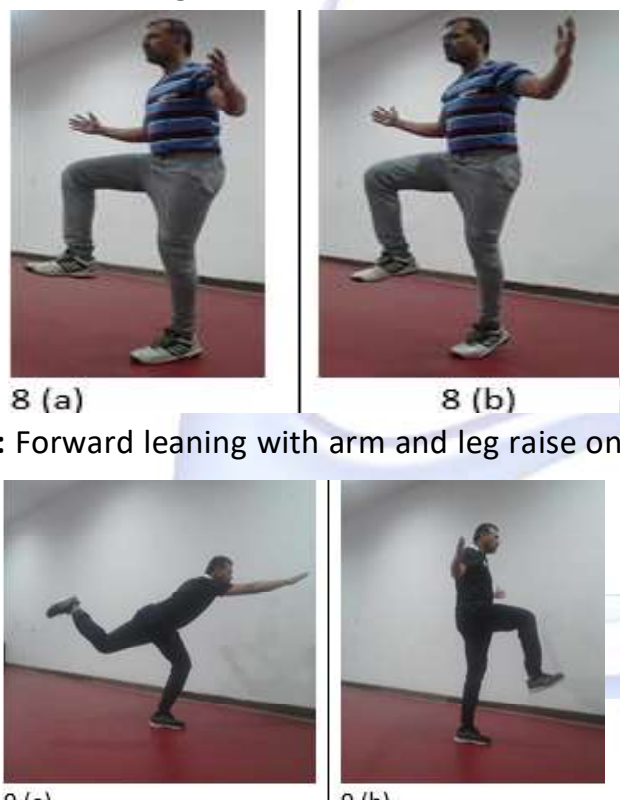

8 (b)

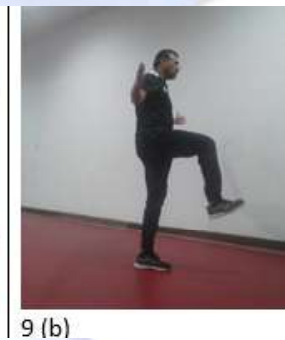

Fig. 10: On the spot hopping on SLB

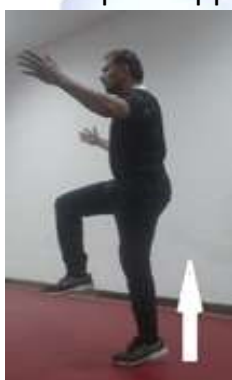

Fig. 11: Forward hopping and progress on SLB

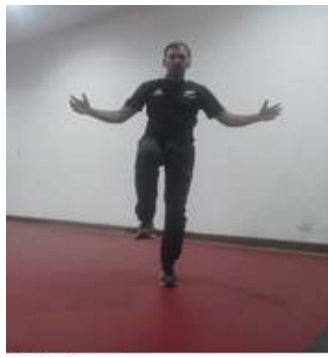

11 (a)

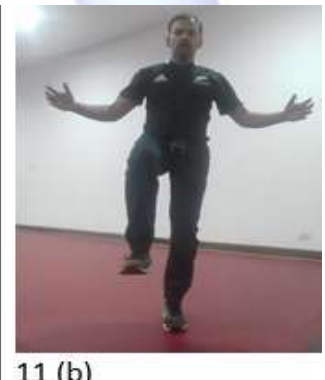

11 (b)

Fig. 12: Side to side hopping on SLB.
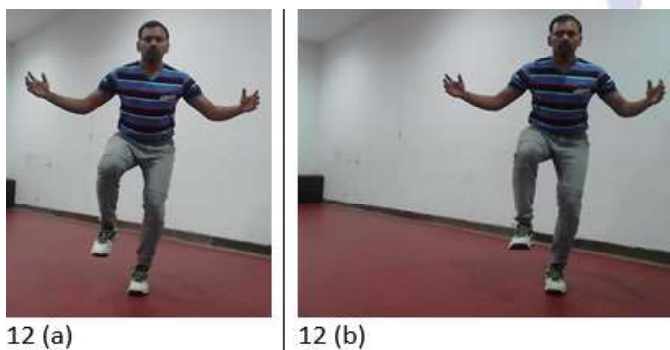

12 (b)
Fig. 13: Zig zag forward hopping and progress on SLB.
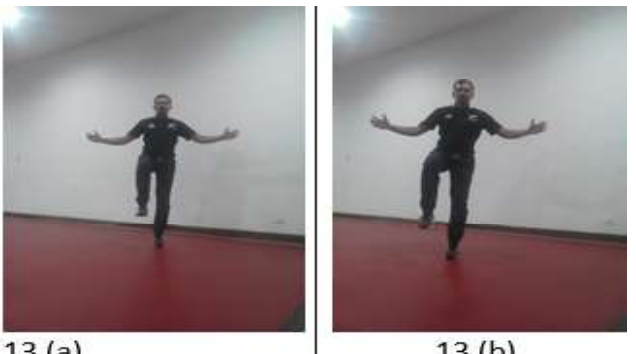

13 (a)

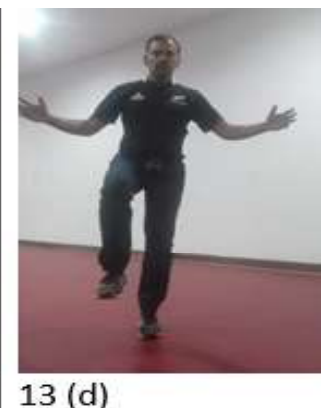

13 (c) 13 (d)

Fig. 14: Stride forward to SLB.

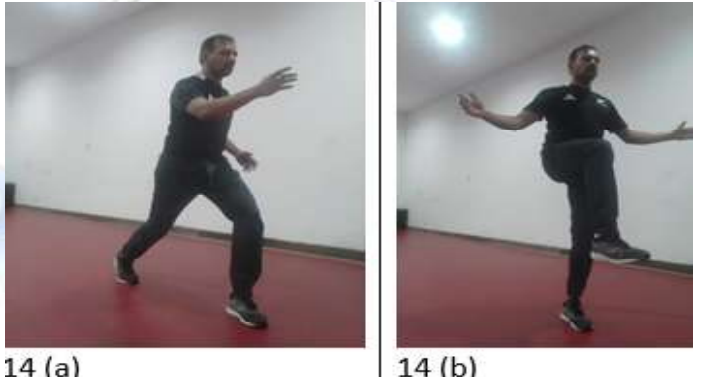

Fig. 15: Stride backward to SLB.

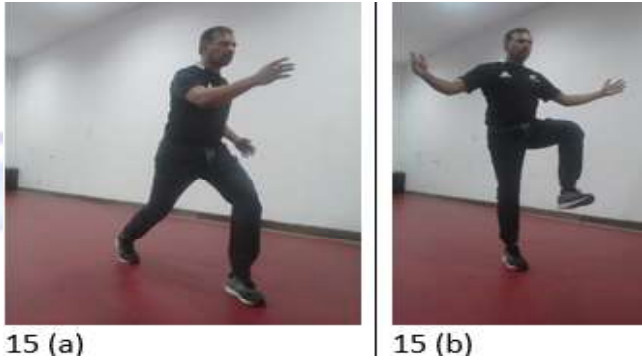

Fig. 16: Stride sideward to SLB (Ipsilateral).

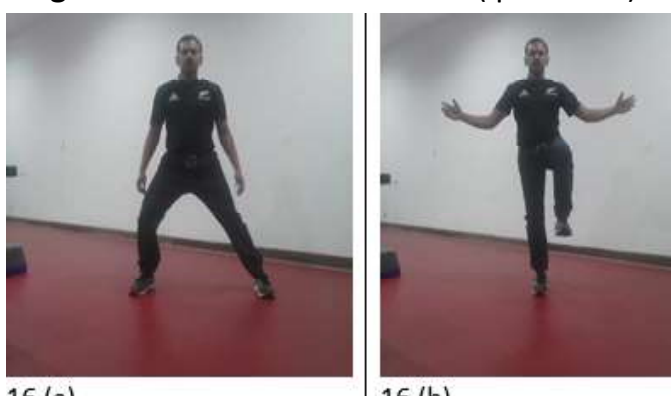

$16(a)$

16 (b)

Fig. 17: Stride sideward to SLB (Contralateral).

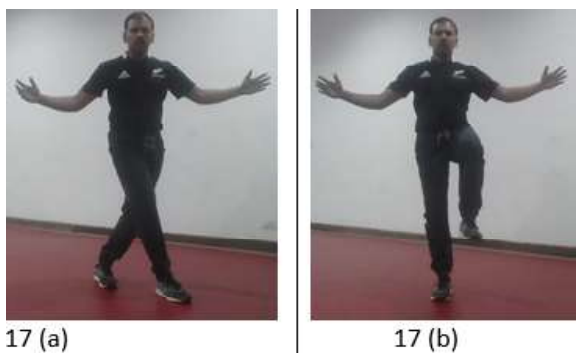


Fig. 18: Step up knee lift to SLB.

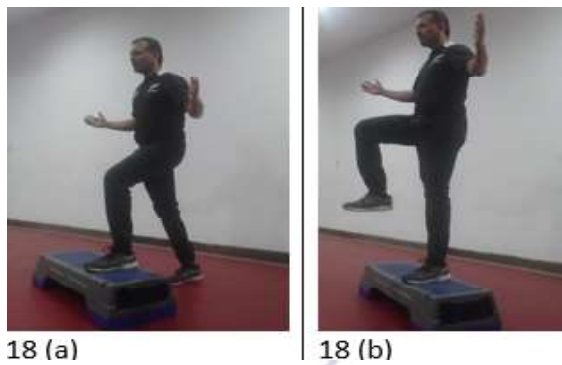

Fig. 19: Step down and reverse step up to SLB.

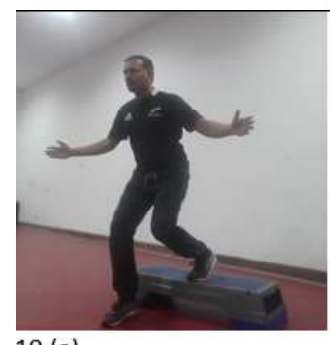

19 (a)

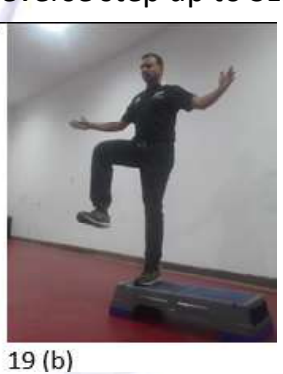

Fig. 20: Sideward bending and side step up to SLB.

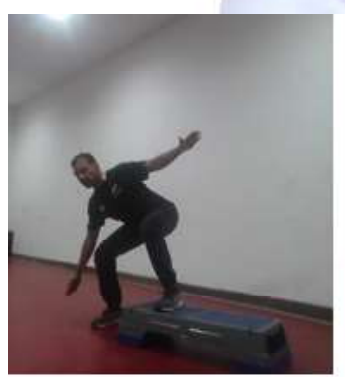

20 (a)

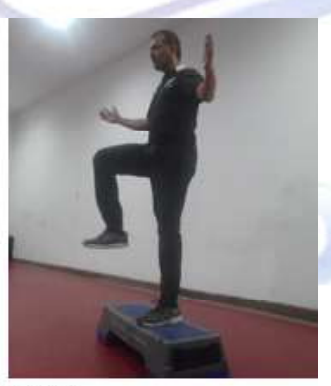

20 (b)

Fig. 21: Perfect SLB freeze and incorrect postural strategies of Support Leg (SL) and Unsupported Leg (UL).

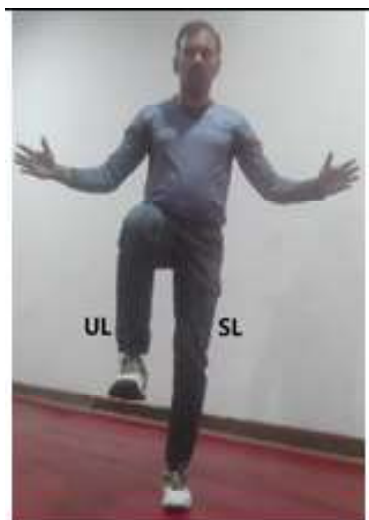

Figure -21 (a)

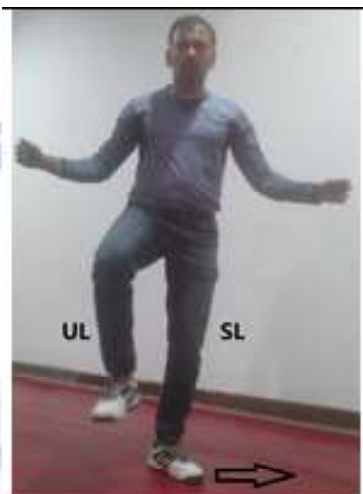

Figure -21 (c)

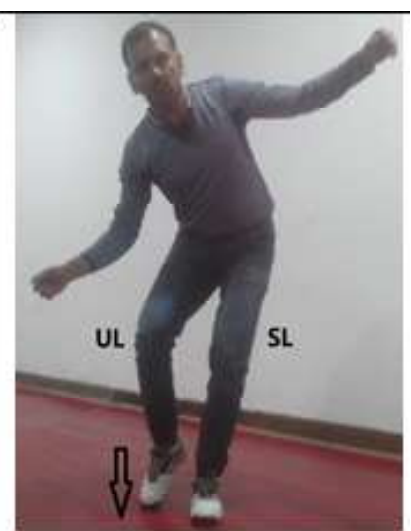

Figure $-21(b)$

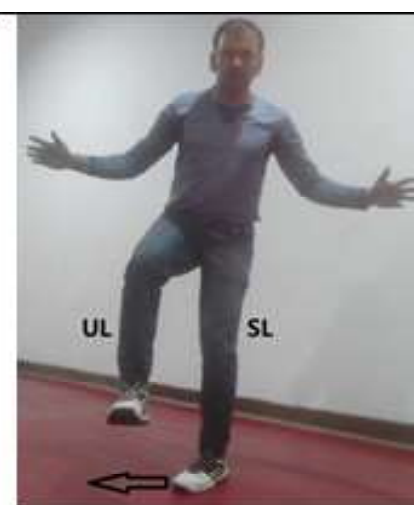

Figure -21 (d)

Table 2: Dynamic SLB rating system.

\begin{tabular}{|c|l|}
\hline $\mathbf{0}$ & $\begin{array}{l}\text { Unable to control SLB even for a second despite applying strategies like (i) Quickly lowering the UL (ii) } \\
\text { Medially or laterally deviating the foot of the SL (iii) Hopping on the SL in any unexpected direction to a } \\
\text { different location. }\end{array}$ \\
\hline $\mathbf{1}$ & Requires multiple lowering of UL and/or multiple hops or deviations of foot of SL to attain SLB freeze. \\
\hline $\mathbf{2}$ & Requires occasional lowering of UL and/or multiple hops or deviations of foot of SL to attain SLB freeze. \\
\hline $\mathbf{3}$ & Requires multiple hops and/or deviations of foot of SL to attain SLB freeze. \\
\hline $\mathbf{4}$ & Requires occasional hops and/or deviations of foot of SL to attain SLB freeze. \\
\hline $\mathbf{5}$ & Perfect SLB freeze without displacing the foot of the SL from its original location. \\
\hline
\end{tabular}

Table 3: Dynamic SLB rating form.

\begin{tabular}{|l|l|l|}
\hline \multirow{2}{*}{ TECHNIQUES } & \multicolumn{2}{c|}{ GRADING } \\
\hline & RIGHT LEG & LEFT LEG \\
\hline Forward lunge to SLB & & \\
\hline Backward lunge to SLB & & \\
\hline Sideward reach to SLB & & \\
\hline Squat to SLB & & \\
\hline Sideward bending on SLB (Ipsilateral) & & \\
\hline Sideward bending on SLB (Contralateral) & & \\
\hline Bend and twist to SLB & & \\
\hline Heel off on SLB & & \\
\hline Forward leaning with arm and leg raise on SLB & & \\
\hline On the spot hopping on SLB & & \\
\hline Forward hopping and progress on SLB & & \\
\hline Side to side hopping on SLB & & \\
\hline Zig zag forward hopping and progress on SLB & & \\
\hline Stride forward to SLB & & \\
\hline Stride backward to SLB & & \\
\hline Stride sideward to SLB (Ipsilateral) & & \\
\hline Stride sideward to SLB (Contralateral) & & \\
\hline Step up knee lift to SLB & & \\
\hline Step down and reverse step up to SLB & & \\
\hline Sideward bending and side step up to SLB & & \\
\hline \multicolumn{1}{|c|}{ TOTAL } & & \\
\hline FINAL IMPRESSION: & & \\
\hline
\end{tabular}

Table 2 shows the scoring system for SLB to be applied for all the twenty assessment techniques, separately for each leg. The perfect SLB for each technique should receive the maximum score if the individual regains the voluntarily altered alignments to the SLB posture without displacing the foot of the support leg $(S L)$ from its original location and able to sustain the SLB for at least one second (SLB freeze) in every successful attempt.

About three to five chances for each technique can be allocated to assess the dynamic SLB of each leg. Table 3 shows the dynamic SLB rating form. The balancing exercises used in this dynamic SLB scale were applied on stable platform with or without shoes on, without using 
any balance training devices or unstable platform. Additional features of these SLB assessment techniques were keeping the eyes open, foot of unsupported leg not fixed on to other leg (but hip flexed up to $90^{\circ}$, knee flexed up to $90^{\circ}$, ankle dorsiflexed during SLB freeze) and hands not locked on to the hips (but the arms abducted, elbows flexed, hands at the level of the shoulder during SLB freeze). This is to ensure safety and freedom to take visual cues and protective/ equilibrium reactions from the upper limbs and the unsupported leg also. The speed of movement and oscillations of the trunk or arms or unsupported leg does not matter in the pursuit of getting score ' 5 ' without displaying the characteristics of scores ' 0 to 4 ' but only the precision of applying suitable brakes to attain SLB freeze (delicate timing of concentric, eccentric and isometric contraction, especially of the muscles of the support leg). The support leg also can be given freedom to undergo minute movements at its hip, knee and ankle and also, the foot of the support leg can be given freedom to tilt in any direction (eversion, inversion, plantar flexion, dorsiflexion) associated with curling of toes, all at its original location itself. The only major stipulation is not to displace the foot of the support leg from its original location in all the exercises used in the assessment in order to obtain the maximum score.

\section{RESULT}

As a preliminary testing, when this assessment scale was built and applied on readily available individuals in the age group of 35 to 50 years old, nine men (Mean body weight $=79 \mathrm{Kg}$, Mean fat percentage $=32$ ) and five women (Mean body weight $=65 \mathrm{Kg}$, Mean fat percentage $=36$ ), who have been exercising two to three days per week under the supervision of exercise professional, they displayed excellent SLB freeze and obtained maximum score of ' 5 ' in almost all the techniques for both the legs. Though these individuals struggled in some techniques at first instance, but in 3 to 5 attempts, they could gain full precision of SLB freeze. As a matter of fact, among nine men, two of them had undergone knee surgery for anterior cruciate ligament repair, one of them was under medications for Myocardial Infarction, two of them were under medications for borderline hypertension and, among five women, one of them had undergone partial hysterectomy and, one of them displayed painful crepitations in right knee. The entire assessment per individual could be completed in 30 to 45 minutes.

\section{DISCUSSION}

Sports and physical activities require periods of time where an individual must rely on a single leg base of support, therefore, the use of single leg tests to measure postural stability in a clinical or research sports medicine settings is both logical and warranted [8]. Balance exercises aim at restoring neuromuscular activation and mechanical stiffness of involved tendons that allow for active joint stability and are usually performed in single-leg stance on training devices with different stability properties [9]. The balancing exercises used in this dynamic SLB assessment scale also anticipate similar outcomes with only exception of doing all of them on stable platform with or without shoes on, without using any balance training devices or unstable platform. When voluntary movements are imposed along with SLB postures, the balance tasks become furthermore challenging and also become suitable enough for assessing the functions and dysfunctions of the body. This dynamic SLB assessment scale can be investigated further by other Physiotherapists for its reliability, validity and correlations. Also, further detailed researches using instrumentations like electromyography can be done based on this SLB scale to study the muscle recruitment patterns and correlate with any other clinical findings, fitness parameters and efficiency of treatment/ exercise programs because the scope and necessity for such meticulous researches have been tremendous. In fact, every muscle participating in SLB has the scope of getting specifically researched to obtain diverse insights, for example, studying the role of hip musculature in SLB as found in various literatures. Hip musculature plays a major role in maintaining postural stability during single leg activities and single leg activities are a key component of almost all functional movements. [10].

Individuals with diminished hip abductor muscle strength demonstrated decreased medial-lateral postural stability, and exhibited a shift toward utilizing an ankle strategy to maintain balance 
during unipedal tasks [11]. The strength of Gluteus Medius is important when the center of mass changes direction unexpectedly, requiring strength and stabilization during unilateral stance [12]. Hip abductor strength may not be the only contributing factor in controlling pelvic stability [13].

It is highly likely to develop various asymptomatic biomechanical dysfunctions of unhealthy ageing at an early age itself like inflexibility of tissues, muscular strength deficits, difficulty in controlling single leg balance, defective postures and functional impairments, all associated with unfavorable changes in the body composition and progressively worsen to an irreversible extent if appropriate interventions are not implemented. Fear of Falling (FOF) and restricted functional activities are not uncommon among the older adults [14]. Unexpected sudden perturbations challenge postural equilibrium and require reactive compensation [15]. There was a significant age dependent decrease in Unipedal Stance Time during both eyes open and eyes closed [16]. Adapting to various situations in exercise could make a margin to control a sudden unknown perturbation for elderly people [17]. Adaptations to SLB exercises could aid in maximizing fitness for healthy ageing by strengthening equilibrium reactions and inculcating confidence to efficiently move against gravitational force, perform the Activities of Daily Living (ADL) and tackle the risky perturbations in various situations at any age, especially during the ageing process.

Static single balance test alone may not suffice especially in the health education for healthy ageing and diagnosis/prognosis of various health disorders, hence the exercises used in this dynamic SLB scale could give detailed information about the balancing potential of all the individuals. Simple 'balance measures' cannot identify specific constraints on the sensorimotor processes underlying postural dyscontrol to customise balance rehabilitation for those constraints, thus, comprehensive evaluation by a clinician skilled at systematically evaluating the impairments and strategies underlying functional performance in postural stability is necessary for optimal balance rehabilitation and fall prevention [18].
There is always an inevitable relationship between diminishing physical capacity (diminished antigravity torque potential) and almost all the diseases affecting human beings, hence both the strategies for prevention and rehabilitation of illnesses should revolve around the clinical condition "Gravitational Torque Deficiency Syndrome" under the legitimate supervision of Physiotherapists and Exercise professionals [19].

Being a simple and time-effective assessment to understand the ageing trajectory, recovery from disease, effectiveness of rehabilitation programs and risk of falling, this dynamic SLB scale can also be used as a self-diagnostic tool after thoroughly learning the methods under the supervision of the exercise professional. Patientdriven self-assessment as a preventive measure might be a solution to reduce the number of patients undergoing a full clinical time-consuming and resource-intensive fall risk assessment [20]. Physiotherapists should engage in developing many non-invasive assessment tools and grading systems to evaluate various key neurobiomechanical components of fitness and healthy ageing. Physiotherapists are fortified to conduct biomechanical analyses by visual observations and this distinct skill of Physiotherapists enables them to make accurate clinical diagnosis with credible rationale in many occasions without even the support of any specialized equipment [21]. Experts should continue exploring feasible, non-invasive and inexpensive diagnostic procedures [22]. Henceforth, the domain of exercise and nutrition have much greater role to play conjointly in the endeavour of refining health education paradigms with the help of innovative assessments and prescriptions apt for the epidemiological fluctuations. Unidirectional epidemiological transitions cannot be trusted anymore because at any time the communicable and non-communicable diseases meet and strongly interact perfectly at one point as 'Epidemiological Intersection' [23].

\section{CONCLUSION}

SLB needs strong and coordinated work from almost all the muscles of the lower limb to ensure stability in all planes, therefore retention of this key neuro-biomechanical asset could fortify healthy ageing pursuits. It is prudent to 
utilize this dynamic SLB assessment scale not only to quantify SLB performance and possibly detect the underlying causes for below-average balance performance of any one lower extremity or both the lower extremities but also to motivate the individuals by giving the highest rating even if the individuals display precise SLB only after multiple trials and errors. It is also important to formulate such numerous simple, inexpensive and non-invasive diagnostic tools in the health education and health care system, particularly to support the objectives of Geriatrics and Gerontology. Due to vast exercising experience or as a result of effective exercise prescriptions, it is highly possible for various individuals to easily obtain the highest scores in this dynamic SLB assessment, so in order to challenge them further, scopes are always available for innovation of further levels of dynamic SLB tasks, for example, by adding external resistance through devices like Dumbbell, Barbell, Elastic Exercise tubes, all preferably should be applied on the stable surface itself keeping safety as the paramount rule.

\section{Conflicts of interest: None}

\section{REFERENCES}

[1]. Ayelet Dunsky, Aviva Zeev, and Yael Netz. Balance Performance Is Task Specific in Older Adults. BioMed Research International. 2017; Article ID 6987017.

[2]. Riemann B. Is there a link between chronic ankle instability and postural instability. J Athl Train. 2002;37(4):386-393.

[3]. Kurz E, Faude O, Roth R, Zahner L and Donath L. Ankle muscle activity modulation during single-leg stance differs between children, young adults and seniors. Eur J Appl Physiol. 2018; 118(2), 239-247.

[4]. Sulaiman A. Alshammari, Abdullatif M. Alhassan, Matar A. Aldawsari, Faisal O. Bazuhair, Fahad K. Alotaibi, Ahmed A. Aldakhil, and Faroq W. Abdulfattah. Falls among elderly and its relation with their health problems and surrounding environmental factors in Riyadh. J Family Community Med. 2018; 25(1), 29-34.

[5]. Alex Joseph, Dhasarathi Kumar, and M. Bagavandas. A Review of Epidemiology of Fall among Elderly in India. Indian J Community Med. 2019; 44(2), 166168.

[6]. Koh SS, Manias E, Hutchinson AM, Donath S, Johnston L. Nurses' perceived barriers to the implementation of a Fall Prevention Clinical Practice Guideline in Singapore hospitals. BMC Health Serv Res. 2008; 18;8:105.
[7]. Tinetti ME, Baker DI, McAvay G, Claus EB, Garrett P, Gottschalk M, Koch ML, Trainor K and Horwitz RI. A multifactorial intervention to reduce the risk of falling among elderly people living in the community. Engl J Med. 1994; 331(13), 821-827.

[8]. Bryan L. Riemann and Randy Schmitz. The relationship between various modes of single leg postural control assessment. Int J Sports Phys Ther. 2012;7(3), 257-266.

[9]. Wolburg, T., Rapp, W., Rieger, J., \& Horstmann, T. Muscle activity of leg muscles during unipedal stance on therapy devices with different stability properties. Phys Ther Sport. 2016;17, 58-62.

[10]. Jaber H, Lohman E, Daher N, Bains G, Nagaraj A, Mayekar P, Shanbhag M, Alameri M. Neuromuscular control of ankle and hip during performance of the star excursion balance test in subjects with and without chronic ankle instability. PLoS One. 2018;13;13(8):e0201479.

[11]. Szu-PingLee and Christopher M.Powers. Individuals with diminished hip abductor muscle strength exhibit altered ankle biomechanics and neuromuscular activation during unipedal balance tasks. Gait \& Posture, 2014; 39 (3), 933 - 938.

[12]. Petr Stastny, James J. Tufano, MS, Artur Golas and Miroslav Petr. Strengthening the Gluteus Medius Using Various Bodyweight and Resistance Exercises. Strength Cond J. 2016;38(3), 91-101.

[13]. Kendall KD, Schmidt $C$ and Ferber R. The relationship between hip-abductor strength and the magnitude of pelvic drop in patients with low back pain. J Sport Rehabil. 2010;19(4), 422-435.

[14]. Pitchai P, Dedhia HB, Bhandari N, Krishnan D, D'Souza NR and Bellara JM. Prevalence, risk factors, circumstances for falls and level of functional independence among geriatric population - A descriptive study. Indian J Public Health. 2019; 63, 21-26.

[15]. Freyler K, Gollhofer A, Colin R, Brüderlin U and Ritzmann R. Reactive Balance Control in Response to Perturbation in Unilateral Stance: Interaction Effects of Direction, Displacement and Velocity on Compensatory Neuromuscular and Kinematic Responses. 2015; PLoS ONE 10(12): e0144529.

[16]. Springer BA, Marin R, Cyhan T, Robert $H$ and Gill NW. Normative Values for the Unipedal Stance Test with Eyes Open and Closed. Journal of Geriatric Physical Therapy. 2007;30 (1), 8-15.

[17]. Yoshitaka Iwamoto, Makoto Takahashi, and Koichi Shinkoda. Muscle co-contraction in elderly people change due to postural stability during single-leg standing. J Physiol Anthropol. 2017; 36, 43.

[18]. Horak F.B. "Postural orientation and equilibrium: What do we need to know about neural control of balance to prevent falls?". Age and Ageing. 2016; 35(2), 7 -11.

[19]. R. Vinodh Rajkumar. Gravitational Torque Deficiency Syndrome (GTDS): A prospective clinical terminology - Part 1. International Journal of Physiotherapy and Research. 2016; 4(5), 1668-1678. 
R. Vinodh Rajkumar. QUANTIFYING THE SINGLE LEG BALANCE USING MULTIPLE DYNAMIC POSTURES ON STABLE SURFACE.

[20]. Rasche P, Nitsch V, Rentemeister L, Coburn M, Buecking B, Bliemel C, Bollheimer LC, Pape HC and Knobe M. - The Aachen Falls Prevention Scale: MultiStudy Evaluation and Comparison. JMIR Aging. 2019;16, 2(1):e12114.

[21]. R. Vinodh Rajkumar. Prevalence of Outward Deviation of Feet in Human Gait: A Non-Participant Observation. Int J Physiother Res 2020;8(1):3378-3387.
[22]. R. Vinodh Rajkumar. Indirect estimation of the step length of walking and running performances on the treadmill. Int J Physiother Res 2020;8(2):3407-14.

[23]. R.Vinodh Rajkumar. Epidemiological Intersection: The Revelation of COVID-19 Pandemic. Int J Physiother Res 2020;8(2):3438-42.

How to cite this article:

R. Vinodh Rajkumar. QUANTIFYING THE SINGLE LEG BALANCE USING MULTIPLE DYNAMIC POSTURES ON STABLE SURFACE. Int J Physiother Res 2020;8(3):3462-3470. DOI: 10.16965/ijpr.2020.130 